\title{
Highly Selective Wearable Smartsensors for Vapor/Liquid Amphibious Methanol Monitoring
}

Hongting Ma, ${ }^{+, \text {II }}$ Yu Jiang, ${ }^{+, \text {II }}$ Junlin Ma, ${ }^{+}$Xinlei Ma, ${ }^{\star}$ Mianqi Xue, ${ }^{\S}$ and Nan Zhu ${ }^{*},+$

${ }^{\dagger}$ Zhang Dayu School of Chemistry, Dalian University of Technology, Dalian, Liaoning 116024, China.

${ }^{\ddagger}$ Department of Che mistry, Ren min University of China, Beijing 100872, P.R. China

${ }^{\S}$ Technical Institute of Physics and Chemistry, Chinese Academy of Sciences, Beijing 100190, China

Email:nanzhu@dlut.edu.cn.

SUPPORTING INFORMATION

\section{Contents}

1. Characterization of the materials

1.1 EDS patterns of GO and Pt/rGO hybrid.

1.2 Size distribution of the Pt NPS in Pt/rGO hybrid.

1.3 TEM of GO hybrid.

2. Mechanism of methanol oxidation process on Pt electrodes

3. Results and Discussion

3.1 Electrochemical property of PET-based sensors in methanol gas

3.2 Electrochemical property of PET-based sensors in methanol liquid

3.3 Selectivity performance of PET-based sensors 
1. Characterization of the materials

1.1 EDS patterns of GO and Pt/rGO hybrid.
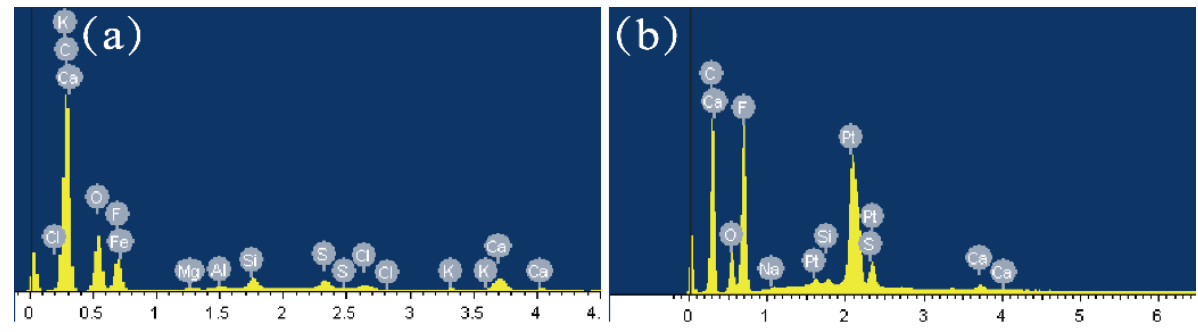

Figure. S1 The Energy Dispersive Spectroscopy (EDS) patterns of (a) GO, (b) Pt/rGO. The weight of commercial PtNPs was $16.22 \%$ 
1.2 Size distribution of the Pt NPS in Pt/rGO hybrid.

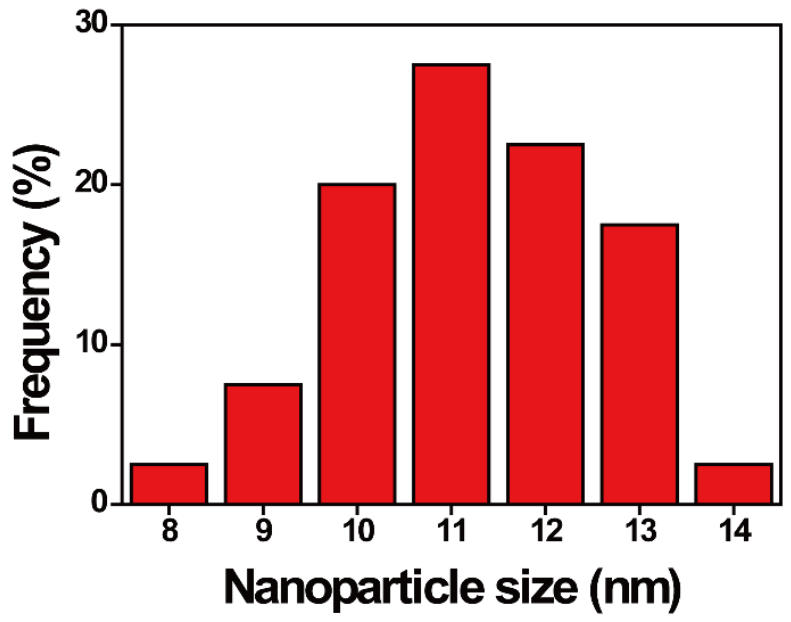

Figure. S2 Size distribution of the Pt NPs in Pt/rGO hybrid. The NPs size distributions by measuring about 250 randomly selected particles, a rough PtNPs distribution from 8-15 nm in diameter was recorded. 
1.3 TEM of GO hybrid.

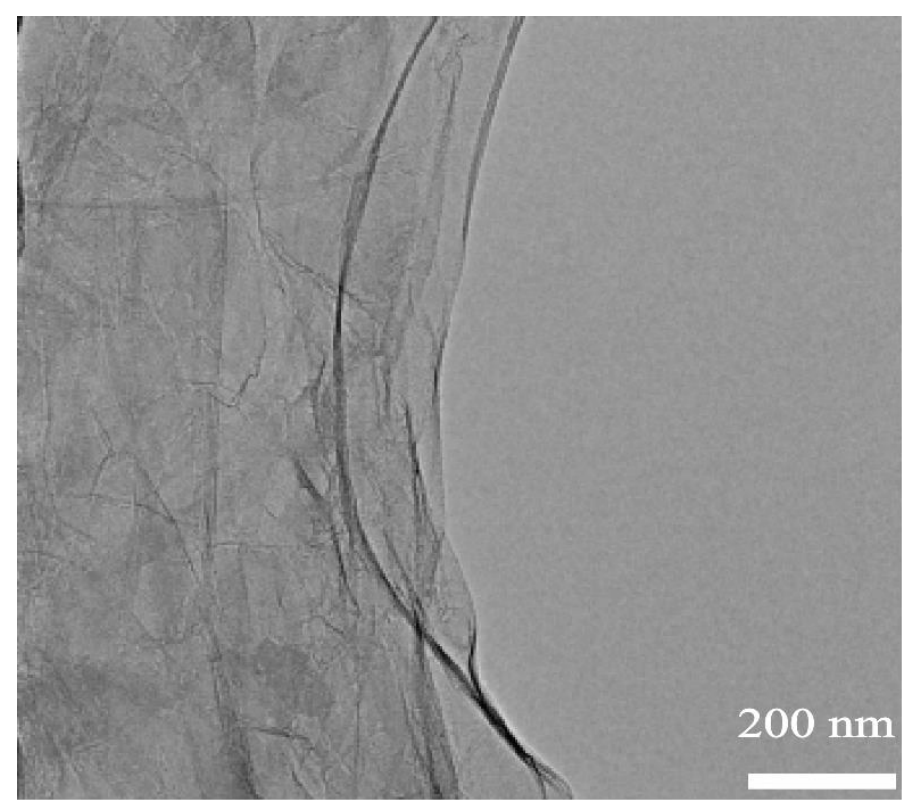

Figure. S3 TEM of GO hybrid. 
2. Mechanism of methanol oxidation process on Pt electrodes

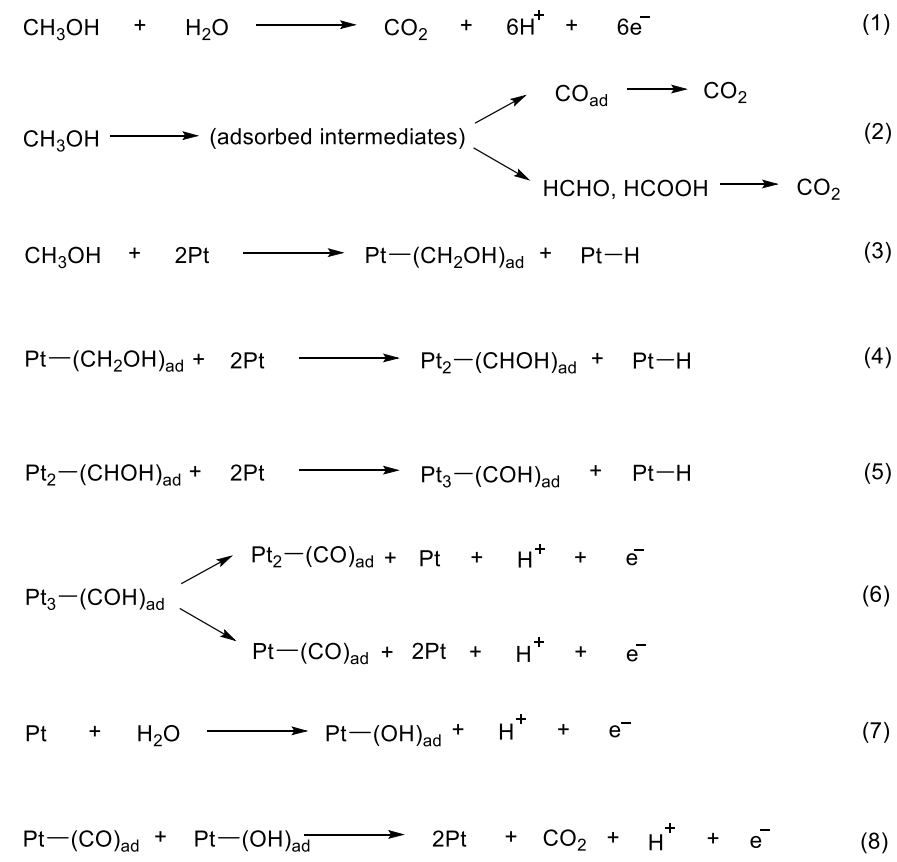

it is reported, the oxidation of methanol is a catalyst-driven six electron transferred electrochemical reaction (equation (1)). As shown in equation (2-8), the total process can be elaborated as a series of parallel reactions. ${ }^{1,2}$ Electrochemical oxidation of methanol is achieved by non-CO and $\mathrm{CO}$ pathway.,3,5

As shown in equation (2), at the beginning of the process, with several neighboring active sites on the surface of Pt catalyst, methanol is adsorbed on it. The reaction can be divided into two ways. On one hand, the adsorbed intermediates are first formed as $\mathrm{CO}$ and further oxidized to $\mathrm{CO}_{2}$ with $\mathrm{O}$-containing species coming from the dissociation of water, which is called $\mathrm{CO}$ pathway; on the other hand, the methanol is oxidized to $\mathrm{HCHO}$ or $\mathrm{HCOOH}$ and further oxidized to $\mathrm{CO}_{2}$, which is named non-CO pathway.

From equation (3-5), hydrogen atoms and methanol molecules exist a competitive adsorption relation. Accordingly, methanol adsorption is relatively easy to occur at the low potential, where neighboring platinum sites remain enough. With the stepwise adsorption of methanol and the dissociation of $\mathrm{C}-\mathrm{H}$ bond, various intermediates $\left(\mathrm{Pt}-\left(\mathrm{CH}_{2} \mathrm{OH}\right)_{\mathrm{ad}}\right.$, $\left.\mathrm{Pt}_{2}-(\mathrm{CHOH})_{\mathrm{ad}}, \mathrm{Pt}_{3}-(\mathrm{COH})_{\mathrm{ad}}\right)$ have been produced one after another. The reaction rate is in the order of $(5)>(4)>$ (3), so that $\mathrm{Pt}_{3}-(\mathrm{COH})_{\mathrm{ad}}$ is the main adsorption product. As shown in equation (6), the dissociation of $\mathrm{Pt}_{3}-(\mathrm{COH})_{\mathrm{ad}}$ has taken place to form $\mathrm{Pt}_{2}-(\mathrm{CO})_{\mathrm{ad}}$ and $\mathrm{Pt}-(\mathrm{CO})_{\mathrm{ad}}$. As the strongly adsorbed species, $\mathrm{Pt}_{2}-(\mathrm{CO})_{\mathrm{ad}}$ and $\mathrm{Pt}-(\mathrm{CO})_{\mathrm{ad}}$ would occupy the platinum active sites, leading to the platinum catalyst poisoning. Besides, at higher potential, the dissociation of water would take place to form $\mathrm{Pt}-(\mathrm{OH})_{\mathrm{ad}}$ (equation $\left.(7)\right)$. Pt- $(\mathrm{CO})_{\mathrm{ad}}$ and $\mathrm{Pt}_{2}-(\mathrm{CO})_{\mathrm{ad}}$ would be removed by Pt- $(\mathrm{OH})_{\mathrm{ad}}$ to release platinum sites again (equation $\left.(8)\right)$. Pt $-(\mathrm{OH})_{\mathrm{ad}}$ could consume Pt- $(\mathrm{CO})_{\mathrm{ad}}$ to reduce the poisoning effect of the catalyst, but the formation of Pt- $(\mathrm{OH})_{\text {ad }}$ is relevant to the electrode potential, which limit the rate for Pt- $(\mathrm{OH})_{\text {ad }}$ consume Pt- $(\mathrm{CO})_{\text {ad }}$ and result incompletely inhibit catalyst deactivation. Finally, the formed intermediates would go further oxidative reaction to form $\mathrm{CO}_{2}, \mathrm{HCHO}$ and $\mathrm{HCOOH}$.

\section{Results and Discussion}

\subsection{Electrochemical property of PET-based sensors in methanol gas}



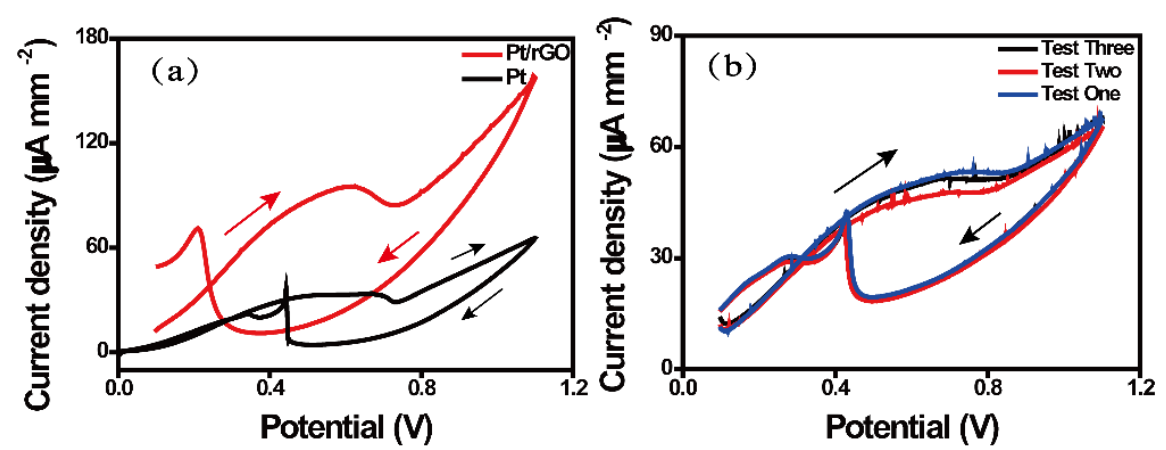

Figure. S4 Electrochemical property of PET-based sensors under methanol vapor environment. (a) CV curves of modified Pt/rGO electrode (red curve) and modified Pt electrode (black curve) at $5 \%$ methanol liquid, scan rate $5 \mathrm{mV}$ $\mathrm{s}^{-1}$. (b) Recoverability of the CV curves during different cycles in 5\% methanol vapor. 

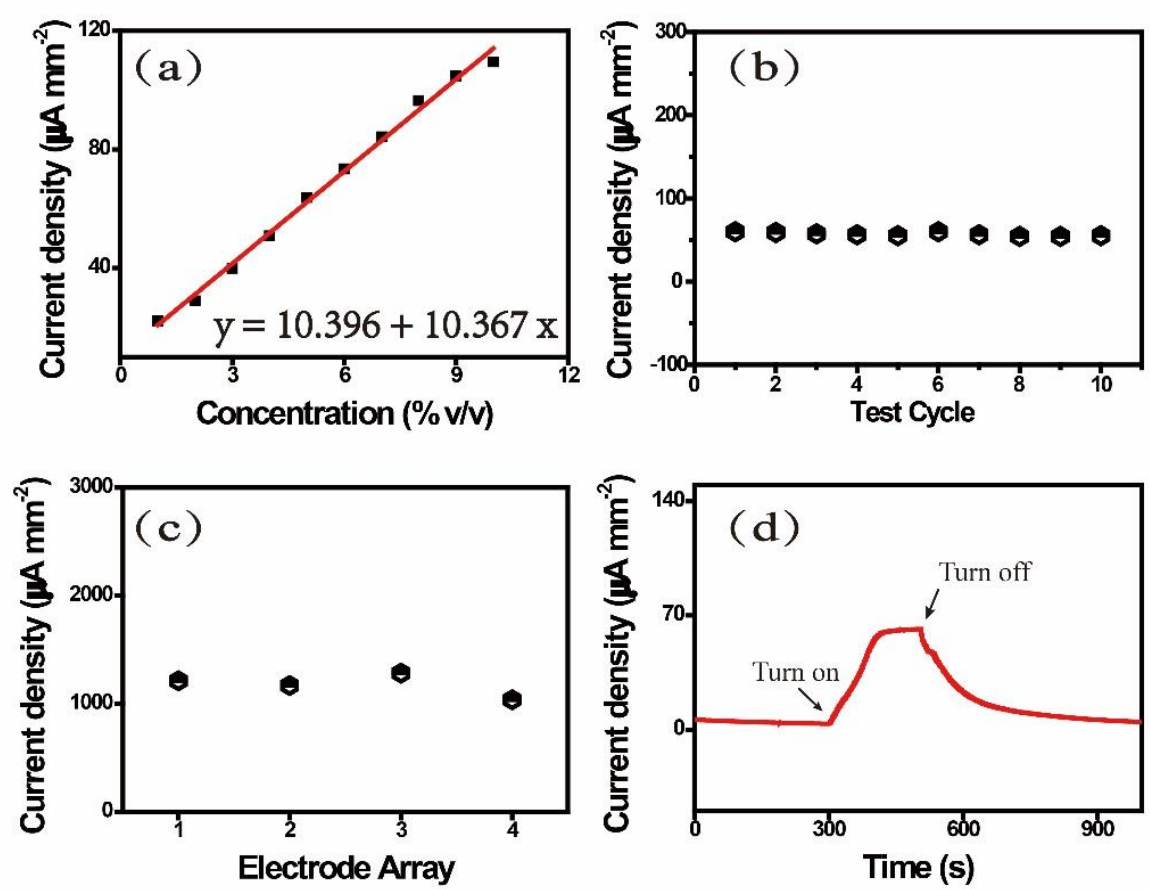

Figure. S5 (a) Linear relationship of the currents collected at $200 \mathrm{~s}$ vs the volume fraction of methanol $(\mathrm{r}=0.99)$. The reproducibility and response time of the methanol vapor senor. (b) Reusability of one electrode during 10 repetitive runs. (c) Reproducibility of different electrode arrays. (d) Response and recovery processes of turn-on and turn-off by the sensor. Sensing system was under $5 \% \mathrm{v} / \mathrm{v}$ methanol vapor condition. 
Table. S1 Comparison of methanol sensing properties of present sensor with the earlier reported resistance- based sensors.

\begin{tabular}{cccccc}
\hline Material & $\begin{array}{c}\text { Operating } \\
\text { temperature }\end{array}$ & Detection Range & $\begin{array}{c}\text { Response Time } \\
(\mathrm{s})\end{array}$ & $\begin{array}{c}\text { Recovery } \\
\text { Time }(\mathrm{s})\end{array}$ & Reference \\
\hline $\mathrm{Pt} / \mathrm{rGO} \mathrm{NPs}$ & $\begin{array}{c}\text { Room } \\
\text { temperature }\end{array}$ & $\begin{array}{c}1-10 \% \\
(\mathrm{v} / \mathrm{v})\end{array}$ & 110.8 & 296.6 & This work \\
\hline $\mathrm{TiO}_{2}$ nanotubes & $300{ }^{\circ} \mathrm{C}$ & $10-1000 \mathrm{ppm}$ & 186 & 222 & 6 \\
\hline $\begin{array}{c}\mathrm{Al} \text {-doped } \mathrm{ZnO} \\
\text { thin films }\end{array}$ & $275^{\circ} \mathrm{C}$ & $100-500 \mathrm{ppm}$ & 280 & 280 & 7 \\
\hline $\mathrm{CuO}$ thin films & $350{ }^{\circ} \mathrm{C}$ & $100-2500 \mathrm{ppm}$ & 235 & 235 & 8 \\
\hline $\begin{array}{c}\mathrm{Co} \mathrm{O}_{4}- \\
\text { intercalated rGO }\end{array}$ & Room & & & & 360 \\
\hline
\end{tabular}



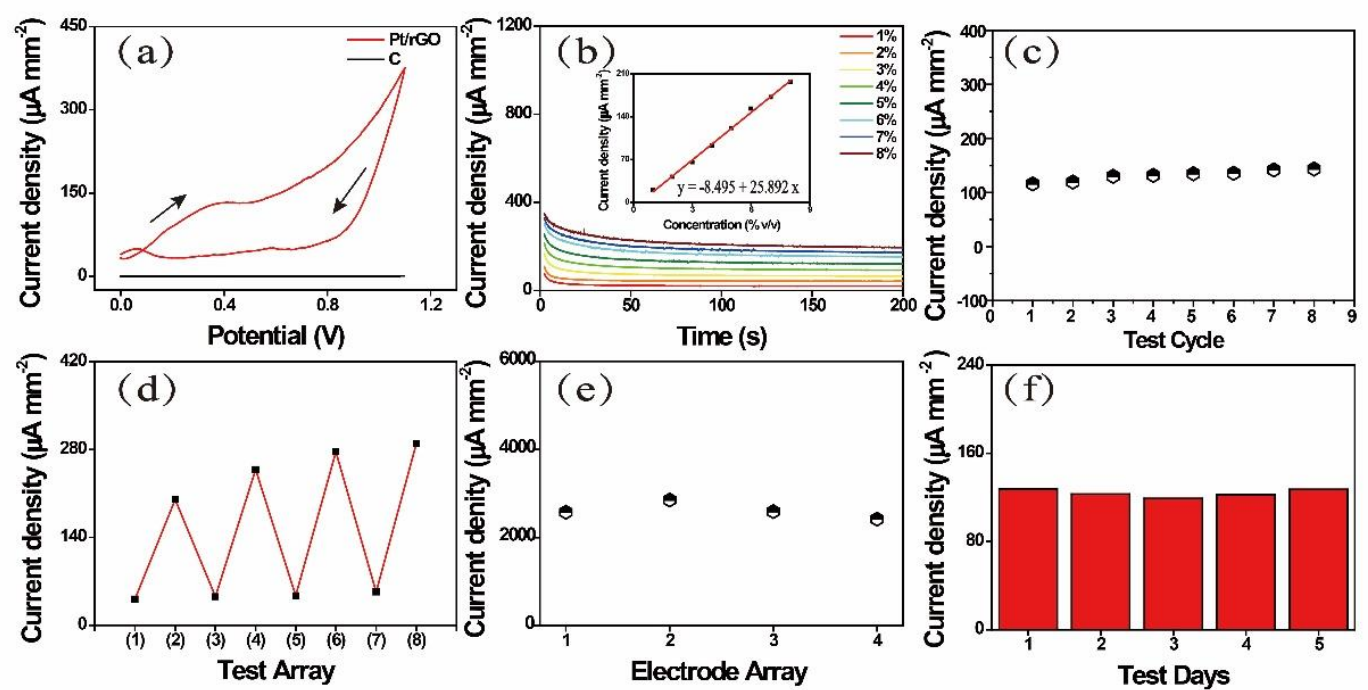

Figure. S6 Electrochemical property of PET-based sensors under methanol liquid environment. (a) CV curves of unmodified electrode (black curve) and modified electrode (red curve) at $5 \%$ methanol liquid, scan rate $5 \mathrm{mV} \mathrm{s}^{-1}$. (b) Amperometric i-t curves at the anodic peak potential of $0.4 \mathrm{~V}$ in the range of $1-8 \%$ (volume fraction) methanol. Inset: Linear relationship of the currents collected at $200 \mathrm{~s}$ vs the volume fraction of methanol ( $\mathrm{r}=0.97)$. (c) Reusability of one electrode during 8 repetitive runs. (d) Recoverability of the sensor arrays as the concentration between 1 and $8 \%$ (volume fraction). (e) Reproducibility of different electrode arrays. (f) Long-time stability during 5 days. (c), (d) and (f) were under $5 \% \mathrm{v} / \mathrm{v}$ methanol liquid condition. 

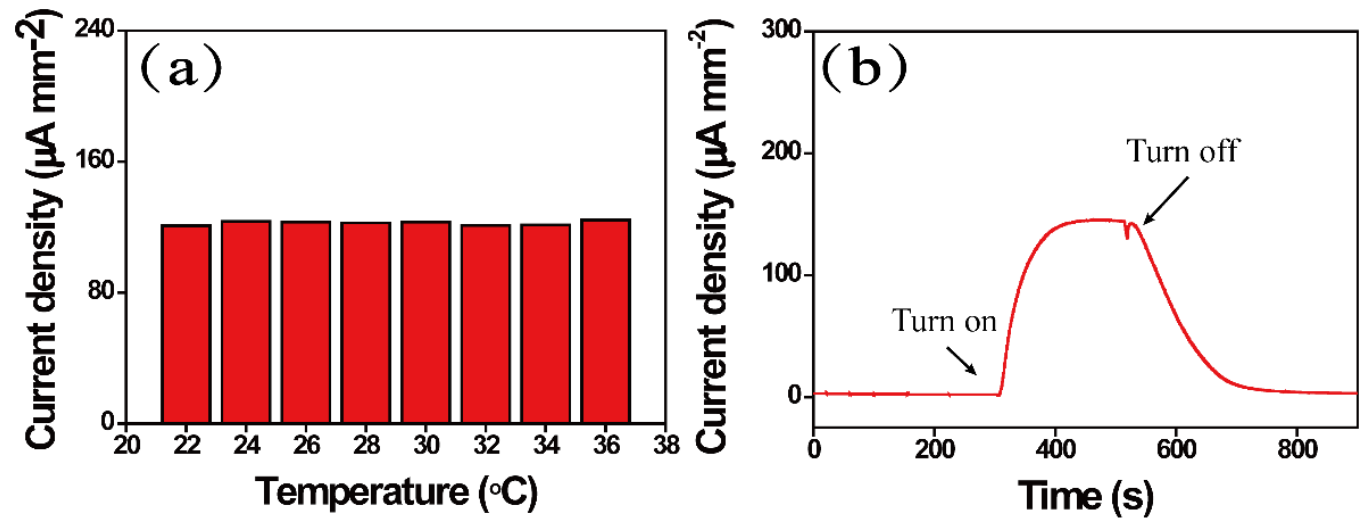

Figure. S7 (a) Temperature from 22 to $36^{\circ} \mathrm{C}$ (every $\left.2{ }^{\circ} \mathrm{Gncreased}\right)$. (b) Response and recovery processes of turn-on and turn-off by the sensor. Sensing performance under $5 \% \mathrm{v} / \mathrm{v}$ methanol liquid condition. 
Table. S2 The comparison of sensing parameters of the methanol sensor in liquid and gas phase

\begin{tabular}{|c|c|c|c|c|c|c|}
\hline \multirow[b]{2}{*}{ Phases } & \multicolumn{2}{|c|}{ Linear Range } & \multicolumn{2}{|c|}{ Environmental adaptability } & \multirow{2}{*}{$\begin{array}{l}\text { Sensitivity } \\
\left(\mu \mathrm{A} \mathrm{mm} \mathrm{m}^{-2}\right)\end{array}$} & \multirow{2}{*}{$\begin{array}{l}\text { Reusability } \\
\text { (test cycle) }\end{array}$} \\
\hline & $\begin{array}{l}\text { Volume } \\
\text { fraction }\end{array}$ & R-Squared & $\begin{array}{c}\text { Temperature } \\
\left(^{\circ} \mathrm{C}\right.\end{array}$ & $\begin{array}{c}\text { Humidity } \\
\text { (\%) }\end{array}$ & & \\
\hline Vapor & $1-10 \%$ & 0.99 & $22-42$ & $15-85$ & 1039.6 & 10 \\
\hline liquid & $1-8 \%$ & 0.97 & $22-36$ & - & 2589.2 & 8 \\
\hline
\end{tabular}


3.3 Selectivity performance of PET-based sensors
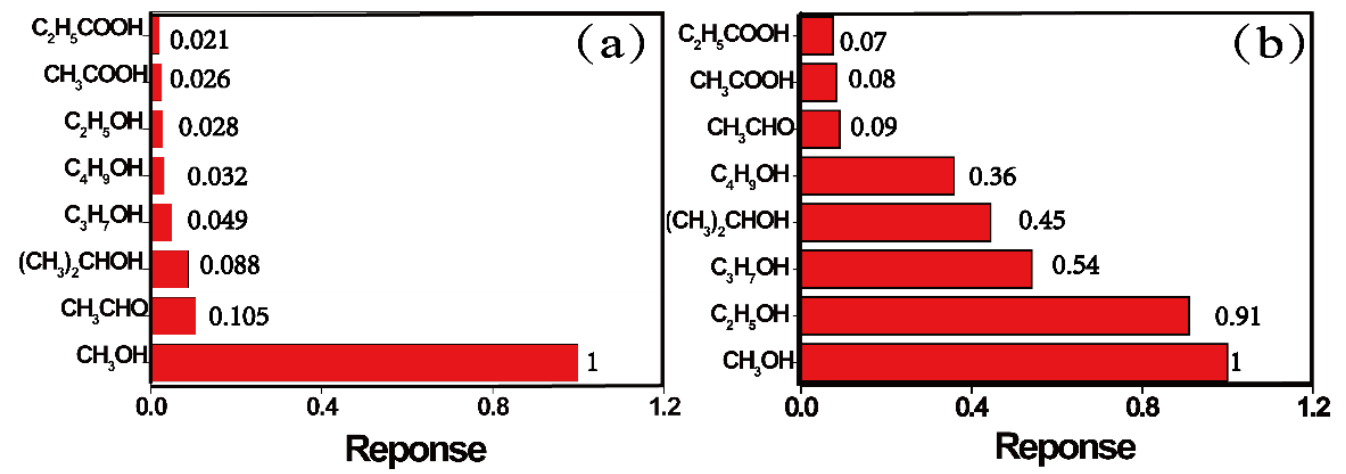

Figure. S8 The selectivity performance of the PET-based methanol sensor among its chemical structure analogues, including methanol, ethanol, isopropanol, $\mathrm{N}$-propanol, N-butanol, propionic acid, acetic acid, acetaldehyde. (a) $5 \%$ VOCs liquid at 0.4 $\mathrm{V}$; (b) $5 \%$ VOCs vapor at $0.6 \mathrm{~V}$. journal's Instructions for Authors for details. 


\section{References}

(1) Zhao, X., Yin, M., Ma, L., Liang, L., Liu, C., Liao, J., Lu, T., Xing, W. Energy Environ. Sci. 2011, 4, 2736;

(2) Iwasita, T. Electrochim. Acta. 2002, 47, 3663-3674.

(3) B. Narayanamoorthy, K. K. R. Datta, M.Eswaramoorthy, S. Balaji, ACS Catal. 2014, 4, 3621-3629;

(4) Y. Jiang, J. Ma, J. Lv, H. Ma, H. Xia, J. Wang, C. Yang, M. Xue, G. Li, N. Zhu, ACS Sens. 2019, 4, 152-160;

(5) W. Gong, Z. Jiang, R. Wu, Y. Liu, L. Huang, N. Hu, P. Tsiakaras, P. K. Shen, Appl. Catal., B 2019, 246, 277-283.

(6) Hazra, A.; Dutta, K.; Bhowmik, B.; Chattopadhyay, P. P.; Bhattacharyya, P. Applied Physics Letters 2014, 105.

(7) Sahay, P. P.; Nath, R. K. Sensors and Actuators B: Chemical 2008, 134, 654-659.

(8) Parmar. M.; Rajanna. K. Int. J. Smart Sens. Intell. Syst. 2011, 4, 710-725.

(9) Chen, N.; Li, X.; Wang, X.; Yu, J.; Wang, J.; Tang, Z.; Akbar, S. A. Sensors and Actuators B: Chemical 2013, 188, 902-908. 